\title{
CHAPTER 5 \\ Climate Change, Air Pollution, and Health: \\ Common Sources, Similar Impacts, and Common Solutions
}

\author{
Veerabhadran Ramanathan
}

Summary We are living in the Anthropocene. Human beings have become a major force by massively polluting the air we breathe as well as the entire atmosphere, which maintains the climate in a habitable zone. Close to one trillion tons of air and climate pollutants are blanketing the earth, and trillions of additional tons will be added this century. Millions of people are dying prematurely every year due to air pollution. If climate pollutant emissions are allowed to continue well into the twenty-first century, global warming and climate change can pose existential threats to Homo sapiens and many other species. The dominant sources of air pollution and climate change are the same: (1) combustion of fossil fuels and biomass for energy; and (2) agriculture, including livestock. Both air pollution and climate change have catastrophic impacts on human health, exposing billions of people to toxic pollution, deadly heat waves, floods, droughts, and fires. Basically, fossil fuel has become an outdated fuel. There is still time to mitigate and avoid the worst consequences. An integral strategy to mitigate air pollution and climate pollution is required because drastic emission cuts in climate pollutants, such as by switching from fossil fuels to abundantly available renewable fuels, will also reduce air pollution. Less wasteful use of fertilizers and greater consumption of a plant-based diet are also required. Technical solutions have to be bolstered by societal transformation solutions to solve the problem in time and transition to a safer Anthropocene.

\section{Science of Air Pollution and Climate Change}

Air pollution and climate change have been the subjects of rigorous scientific enquiry for more than a century. The focus of air pollution studies has been primarily on the impacts on human and ecosystem health. Climate change studies have

\footnotetext{
V. Ramanathan $(\bowtie)$

Scripps Institution of Oceanography, University of California at San Diego,

La Jolla, CA, USA

e-mail: vramanathan@ucsd.edu
} 
largely focused on impacts on the physical climate system, including temperature, weather, glaciers, and sea level rise, among others. Only during the last two decades has the integrated nature of the air pollution and climate change problems been recognized; that is, both air pollution and climate change affect public health as well as the health of the ecosystem. The dominant sources of air pollution and climate change are the same: burning of fossil fuels; burning of solid biomass, including forests; and agriculture emissions. Air pollutants also have a strong influence on climate change. Likewise, weather extremes caused by climate change affect health in major ways. These linkages between air pollution, climate change, and health of the people and the ecosystem are explored in this chapter, as well as many other chapters in this book.

The primary climate warming pollutant gases are carbon dioxide, methane, ozone, nitrous oxide, and halocarbons. The primary air pollutants are particles and ozone. The primary air pollution particles are sulfates, nitrates, black carbon (soot), and organics. All particles intercept sunlight and cause a dimming of sunlight at the surface. Black carbon absorbs sunlight and is one of the largest climate warming pollutants. All other particles act like mirrors and reflect sunlight back to space, which causes cooling.

Air Pollutants: Air pollution particles are very small in size, ranging from nanometers (billionth of a meter) to $10 \mu \mathrm{m}$ (micrometers). A micrometer is a millionth of a meter. For reference, a human hair ranges from $20 \mu \mathrm{m}$ to larger sizes. Air pollution particles sampled from the air typically consist of sulfates and nitrates from fossil fuel burning; black carbon from diesel combustion and biomass burning; organic carbon from fossil fuel combustion and biomass burning; and mineral dust and sea salt particles from natural sources. These particles are too tiny to see with our eyes. The particles scatter sunlight, which gives a hazy appearance to the sky; it is this hazy sky that we perceive as air pollution. Some particles, such as black carbon, also trap sunlight in blue and UV wavelengths, which gives a brownish appearance to the hazy sky and is called brown clouds.

Ozone is also an air pollutant, but it is a gas. Human activities do not emit ozone, but they emit pollutant gases such as carbon monoxide, nitrogen oxides (NOx), nitrous oxide, and methane, which produce ozone in the air. Ozone is also a major climate warming pollutant.

Air pollution is transported far and wide by atmospheric winds. For example, air pollution from the east coast of China travels within 5-7 days to the west coast of North America; air pollution from the east coast of the United States travels to Europe in less than five days. The lifetime of an air pollution particle in the air ranges from a few days to a few weeks depending on the location, the season, and the altitude. The particles are removed from the air either by rain or by directly depositing on the surface. These are important facts because solutions to the air pollution problem often require local, regional, national, and even global actions.

Climate Pollutants: The major climate pollutants are gases that absorb and emit infrared (heat) radiation. Because their lifetimes range from a decade to centuries, greenhouse gases cover the planet like a blanket. A blanket on a cold winter night 
keeps us warm by trapping body heat. Likewise, the greenhouse blanket in the air traps the infrared heat emitted by the surface and the atmosphere and warms the planet. The magnitude of the infrared heat trapping can be estimated from the quantum mechanics of the gas molecules and verified by laboratory data. These infrared heat-trapping gases are called greenhouse gases.

Greenhouse gases have multiple sources. The sources of carbon dioxide, which is a major climate pollutant, are fossil fuel combustion and biomass burning (mainly deforestation and cooking with firewood). For methane, the sources include fossil fuel (natural gas) production and transport, agriculture (rice cultivation), cattle breeding, farm manure, landfills, and sewage. Nitrous oxide is primarily from fertilizers, whereas the main sources of halocarbons are refrigerants. Greenhouse gases stay in the air for months (ozone) to decades (methane and some halocarbons) to a century (nitrous oxide and some halocarbons). Carbon dioxide is the most insidious climate pollutant because it has multiple time scales, ranging from decades to centuries to thousands of years. For example, we are likely still breathing carbon dioxide emitted in the nineteenth century by the improved steam engine invented by the famous British engineer James Watt. In that sense, carbon dioxide is immortal when judged by human time scales. Because of their long lifetimes (more than a decade), greenhouse gases (except ozone) emitted on any corner of the planet can travel to the rest of the planet, trap heat, and impact the climate globally. That is why the phenomenon is called global warming.

\section{Air Pollutants and Climate Pollutants: Similar Impacts}

Both air pollution and climate change have large negative impacts on the health of people and of the ecosystem.

\section{Air Pollution Impacts}

Health Impacts of Air Pollution: When inhaled, tiny nano- to micrometer sized particles enter the lungs, the bloodstream, and even the brain (GBD 2013 Risk Factors Collaborators 2015). Air pollution is the fourth largest risk factor to global health, after high blood pressure, dietary risks, and smoking. It also is the biggest environmental health risk factor.

Epidemiologists have classified air pollution particles under two categories: ambient (outdoor) air pollution (AAP) and household air pollution (HAP). In principle because of wind-driven mixing, AAP and HAP should be similar. However, in rural households in Asia, Africa, and South America, cooking is mostly done by burning solid fuels such as firewood, coal, dung, and crop residues in rudimentary stoves. The incomplete combustion of solid fuels in such stoves gives rise to smoke consisting of black carbon and organic carbon particles. Due to poor ventilation, the 
particles are concentrated inside homes, and this has a major impact on the health of the poorest three billion who rely on such cooking. Every year, at least three million succumb to indoor inhalation of HAP. Ultimately, however, the smoke particles escape outdoors, become part of ambient air pollution, and kill even more.

The inhalation of outdoor air pollution causes millions (7-9.5 million) of premature deaths in addition to exposing more than six billion people to adverse health effects. The health effects of air pollution are documented extensively in many chapters of this book.

Ecosystem Impacts of Air Pollution: The impacts of air pollution on ecosystem health include the following:

- Soil acidification due to the acidity of precipitation (acid rain) caused by sulfuric and nitric acids, mostly from fossil fuel combustion;

- Eutrophication of lakes and rivers by NOx (from fertilizers and fossil fuels);

- More than one hundred million tons of damaged crops each year due to ozone exposure (mainly fossil fuels).

Climate Impacts of Air Pollutants: Air pollution has major impacts on the climate, particularly on precipitation.

1. Global Dimming, Monsoon Weakening, and Drying: Air pollutant particles intercept sunlight and reduce the amount of sunlight at the surface, which is commonly known as Global Dimming. The dimming leads to a decrease in evaporation from the oceans, which results in a decrease in precipitation, thus leading to droughts. The deadly multi-decadal Sahelian drought during the $1960 \mathrm{~s}$ to the 1980s was attributed in part to the dimming of the North Atlantic Ocean by sulfate and nitrate aerosols from Europe. This asymmetric dimming of the North Atlantic shifted the equatorial rain belt southwards, away from the Sahelian latitude belt (Rotstayn \& Lohmann, 2002). Numerous studies have attributed the decrease in the Indian summer monsoon rains to dimming by widespread atmospheric brown clouds (Ramanathan et al., 2005), which consist of black carbon (soot), sulfates, nitrates, and organics particles that preferentially form over the northern Indian Ocean compared with the southern Indian Ocean.

2. Warming Particles: In addition, black carbon (soot) aerosols from diesel and wood burning are the strongest absorbers (per mass) of solar radiation and contribute to warming (Ramanathan \& Carmichael, 2008). For example, a ton of black carbon from diesel vehicles has the same warming effect as that of 2000 tons of carbon dioxide. The deposition of black carbon has been shown to significantly enhance the solar heating of snow-capped surfaces over Tibetan-Himalaya glaciers, arctic sea ice, and glaciers (Xu et al., 2016).

3. Cooling Effects: Aerosols also have a large cooling effect on the climate. Sulfates, nitrates, and some organics particles primarily scatter sunlight, some of which is reflected back to space instead of being absorbed by the surface, thus exerting a global cooling effect. This aerosol cooling effect has masked (offset) as much as $40 \%$ of the warming effect of greenhouse gases. 
4. Disruption of Global Weather Patterns: Because of their short lifetimes, the cooling as well as the warming aerosols are more concentrated over land than over oceans, as well as more concentrated over the northern hemisphere (because it is more populated) than over the southern hemisphere. This asymmetric effect disrupts the weather patterns because they are driven by temperature gradients between the land and ocean and between the north and south. One such disruption is associated with a tropics-wide circulation called the Hadley circulation, which originates in the tropical region and culminates in the sub-tropical regions $\left(20^{\circ}\right.$ latitude to $35^{\circ}$ latitude) by bringing dry upper atmosphere air downwards. This descending dry air is responsible for many of the major widespread desert regions, such as the Sahara and other major arid regions in Middle East.

\section{Climate Pollution Impacts}

Since 1750, we have emitted 2.2 trillion tons of carbon dioxide, $45 \%$ of which is still in the atmosphere. In addition, methane has been emitted from fossil fuels and a number of other sources, halocarbons (CFCs, HFCs, etc.) from refrigerators and air conditioners, ozone-producing pollutant gases from vehicle exhaust, and nitrous oxide from fertilizers. In addition, the black carbon emitted by diesel vehicles and biomass burning warms the planet. Among these non- $\mathrm{CO}_{2}$ climate warming pollutants, methane, halocarbons, nitrous oxide, and black carbon are popularly known as super pollutants; they are, per ton of emissions, 25 (methane) to 2000 times (halocarbons and black carbon from diesel) more potent than $\mathrm{CO}_{2}$. Among these super pollutants, methane, HFCs (one form of halocarbon), and black carbon are known as short-lived climate pollutants because their lifetimes are much shorter than that of $\mathrm{CO}_{2}$, which ranges from a century to thousands of years. Methane's lifetime is approximately 11 years, the lifetimes of HFCs range from 10 to 20 years, whereas the lifetime of black carbon ranges from days to weeks.

To date, the climate has warmed by approximately $1{ }^{\circ} \mathrm{C}$. The magnitudes of warming are always referred to in terms of the temperature of the planet before 1900. The contribution of $\mathrm{CO}_{2}$ to this warming is about $50 \%$, with non- $\mathrm{CO}_{2}$ pollutants accounting for the other $50 \%$. However, future warming is expected to be dominated by $\mathrm{CO}_{2}$ increases.

Present and Future Global Warming: Climate models are able to simulate the observed surface warming of $1{ }^{\circ} \mathrm{C}$. This by itself is not sufficient to validate the simulations or verify the science of climate change. However, climate models are also able to simulate the following observed climate changes: the penetration of this warming to ocean depths of up to a kilometer, the warming of the atmosphere up to about $15 \mathrm{~km}$, increased humidity in the atmosphere, the retreat of the arctic sea ice, and increases in sea level, among other changes. In addition, climate models predicted these observed changes decades ago, back in the 1970s and 1980s (e.g., 
Madden \& Ramanathan, 1980). The warming has been predicted (Ramanathan \& $\mathrm{Xu}, 2010)$ to pass $1.5^{\circ} \mathrm{C}$ by 2030 and exceed $2{ }^{\circ} \mathrm{C}$ by 2050 .

Global Warming to Climate Change: As the atmosphere warms, humidity increases by about 7\% near the surface and 10-20\% aloft. Atmospheric thermodynamic energy increases in proportion to the increase in humidity. The increase in energy leads to stronger storms and more intense hurricanes, and these extreme events alter the global wind patterns. When the storms get stronger in some locations, it leads to drying and less precipitation in other locations. This redistribution happens in such a manner that wet regions get wetter and dry regions get drier. The dry regions are typically in the sub-tropical regions between $25 \mathrm{~N}$ and $40 \mathrm{~N}$. Because of the intensification of the water cycle of the atmosphere, global warming leads to a substantial increase in the severity of storms, floods, droughts, fires, and heat waves, among other extreme events.

Predictions for the future show a range of probabilities, as illustrated in Fig. 5.1. The red and brown curves are the projections for the baseline scenarios with unchecked emissions. The green curve is the projected warming for 2100 with the

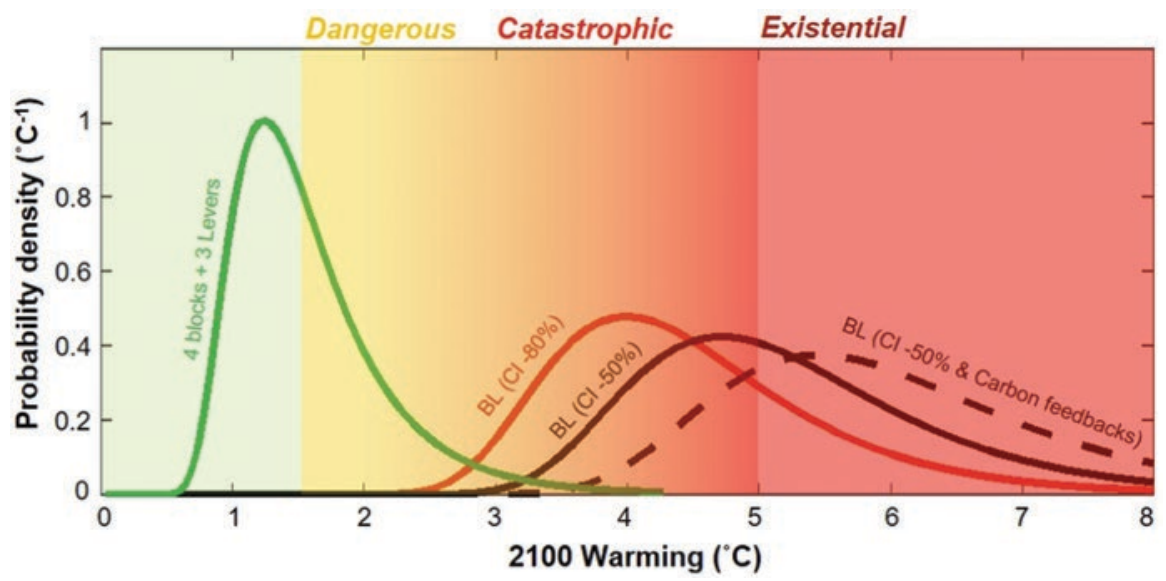

Fig. 5.1 Projected warming for four different scenarios from preindustrial to 2100 as adapted from Xu and Ramanathan (2017). The warming is given in terms of the probability distribution instead of a single value because of uncertainties in climate feedbacks, which could make the warming larger or smaller than the central value shown by the peak probability density value. The three curves on the right side indicated by BL (for baseline) denote the projected warming in the absence of climate policies. BL (CI-80\%) represents the scenario in which the energy intensity (the ratio of energy use to economic output) of the economy decreases by $80 \%$ compared with its value for 2010 . In BL (CI-50\%), the energy intensity decreases by only $50 \%$. These scenarios bound the energy growth scenarios proposed by IPCC-WGIII (2014). The right extreme curve is the BL (CI$50 \%$ ) case. The carbon cycle feedback uses IPCC recommended values for the reduction in $\mathrm{CO}_{2}$ uptake by the oceans as a result of the warming, the release of $\mathrm{CO}_{2}$ by melting permafrost, and the release of methane by wetlands 
mitigation measures described in a companion chapter in this book (Chap. 25). With unchecked emissions, the end-of-century warming can be in the range of $2.5-8{ }^{\circ} \mathrm{C}$.

Risk Categories of Climate Change: The warming has been categorized (following Xu and Ramanathan 2017 and the climate risk assessment IPCC reports) under three risk categories: dangerous risk $\left(>1.5^{\circ} \mathrm{C}\right)$, catastrophic risk $\left(>3{ }^{\circ} \mathrm{C}\right)$, and existential risk $\left(>5^{\circ} \mathrm{C}\right)$.

Dangerous Risk $\left(1.5-3{ }^{\circ} \mathrm{C}\right)$ : Based on data presented in $\mathrm{Xu}$ and Ramanathan (2017), the $1.5^{\circ} \mathrm{C}$ threshold will be crossed by 2030 with a $50 \%$ probability.

- The $1{ }^{\circ} \mathrm{C}$ warming witnessed as of now has already led to the following impacts: The likelihood of extreme events (defined as 3-sigma events), including heat waves, has increased tenfold in recent decades (WMO, 2016). Human beings are extremely sensitive to heat stress. For example, the 2003 European heat wave led to about 70,000 premature mortalities (Mitchell et al., 2016). Hurricanes have become about 25\% more intense (Holland \& Bruyère, 2013). Dry areas worldwide have increased from about $15 \%$ during mid-twentieth century to about $30 \%$ by the first decade of the twenty-first century. The number of disastrous floods have increased from less than 50 per year during the mid-twentieth century to more than 150 during the first decade of the twenty-first century.

- With an increase of another $0.5^{\circ} \mathrm{C}$ above the $1{ }^{\circ} \mathrm{C}$ warming we have already experienced, the underlying dynamic and thermodynamic forces that linked the $1{ }^{\circ} \mathrm{C}$ warming with weather extremes described previously will intensify by another $50 \%$. Warming in the range of $1.5{ }^{\circ} \mathrm{C}$ will subject half of the world's population every other year to regional summer mean temperatures that exceed those of the historically hottest summers (Mueller et al., 2016).

- During the last interglacial period about 130,000 years ago, called the Eemian, the planet was warmer than the preindustrial climate by less than $1{ }^{\circ} \mathrm{C}$. However, this small warming was sufficient enough to raise the sea level by about $6 \mathrm{~m}$.

- During the first decade of the twenty-first century, tropical forests have become net sources of $\mathrm{CO}_{2}$ (Baccini, 2017). If this persists and expands to other forests, forests can become a large source of carbon pollution.

- The last, but very important, issue concerns climate justice: Numerous island nations, including the Maldives and low-lying nations like Bangladesh, will be facing existential threats with a sea level rise of just 1-2 $\mathrm{m}$.

Catastrophic Risks $\left(3-5^{\circ} \mathrm{C}\right)$ : With unchecked emissions, there is a $10 \%$ probability of the warming reaching catastrophic levels by 2050 and a greater than $50 \%$ probability of reaching catastrophic levels before 2100. Catastrophic risks have been defined by some economists as follows: The magnitude of the change is too large and the velocity of that change is too rapid for adaptation. The first major concern with the $3-5{ }^{\circ} \mathrm{C}$ warming is the issue of tipping points. Several studies have concluded that $3-5^{\circ} \mathrm{C}$ global warming is likely to be the threshold for tipping points such as the collapse of the western Antarctic ice sheet, disappearance of the sea ice, disruption of the deep-water circulation in the North Atlantic, dieback of Amazon rainforests and boreal forests, collapse of the West African monsoon, and world 
forests turning into net sources (instead of sinks) of carbon dioxide, among others. The category of "Catastrophic Risk" is also justified by the burning embers diagram from IPCC, in which it categorized climate risks under the following five reasons for concern (RFCs): risks to natural systems, risks of extreme weather events, distribution of impacts between regions of the world, aggregate impacts, and risks of large-scale discontinuities. For warming in the range of $3-5{ }^{\circ} \mathrm{C}$, all RFCs were ranked as a high-risk category, with two of them ranked as very high. The IPCC burning embers diagram does not extend beyond $5{ }^{\circ} \mathrm{C}$. Warming in the range of $3-5{ }^{\circ} \mathrm{C}$ can have the following health impacts on people and ecosystems:

- Extreme heat waves with effective (combination of temperature and humidity) temperatures greater than $55^{\circ} \mathrm{C}\left(131^{\circ} \mathrm{F}\right)$ are projected (Russo, Sillmann, \& Sterl, 2017) to be routine phenomena when global warming exceeds $4{ }^{\circ} \mathrm{C}$.

- Exposing more than 7 billion people to deadly heat stress (Mora et al., 2017).

- Exposing 2.5 billion people to vectorborne diseases (Proestos et al., 2015).

- Subjecting approximately $20 \%$ (Urban, 2015) to 37\% (Thomas et al., 2004) of species to extinction. Climate change interacting with other established drivers of extinction, such as habitat destruction and commercial exploitation of valuable species, can lead to another mass extinction involving $75 \%$ of species (Barnosky, 2015).

- About 30-44\% of the planet's land areas would be exposed to drying (Cook, Smerdon, Seager, et al., 2014) with warming of 3-4 ${ }^{\circ} \mathrm{C}$, accompanied by severe drought conditions over Europe, the eastern United States, southeast Asia, and most of the Amazon region. Food security will be severely threatened.

Existential Risks $\left(>5^{\circ} \mathrm{C}\right)$ : With unchecked emissions of climate pollution, there is at least a $10 \%$ probability for climate change to pose existential threats to Homo sapiens and all other species.

IPCC risk discussions, as shown in the burning embers diagram, do not extend beyond $5{ }^{\circ} \mathrm{C}$. When all of the risks described under the dangerous and catastrophic risk categories are summed, it is clear that the entire planet and all of the global population will be severely impacted. The last time the planet was warmer by $5-8{ }^{\circ} \mathrm{C}$ (as shown in Fig. 5.1) was 35 million years ago, when the $\mathrm{CO}_{2}$ concentration was around 1000 parts per million (Pagani et al., 2011). The planet was ice free, including over the Antarctic, with an implied sea level rise of more than $50 \mathrm{~m}$. It is the combination of multiple catastrophic changes that compelled us (Ramanathan et al., 2017; Xu \& Ramanathan, 2017 ) to conclude that warming in excess of $5{ }^{\circ} \mathrm{C}$ will pose existential threats.

Ethics and Justice Issues: The catastrophic and existential risks raise major ethical issues. More than $50 \%$ of climate pollution is caused by the wealthiest one billion people, while the poorest three billion people emit only $5 \%$ of the climate pollution (Dasgupta \& Ramanathan, 2014; Ramanathan, PAS-PASS workshop, 2014). As described in numerous IPCC reports and other reports, the poor will suffer the worst consequences of climate change. Already today, more than 20 million people are displaced each year from weather extreme events. In addition to this 
intra-generational equity issue, there is huge inter-generational equity because climate change impacts, such as the melting of glaciers and sea level rise, are irreversible for centuries or longer, affecting generations unborn.

\section{Concluding Remarks: Common Solutions}

Both air pollution and anthropogenic climate change problems have been studied for more than a century. However, air pollution science has enjoyed dramatic policy successes. Air pollution emissions have been reduced dramatically, by as much as $70 \%$ for some pollutants (Samet, Burke, \& Goldstein, 2017) in the USA and in other industrialized nations, by deliberate policy actions. The policy actions in the USA were mainly motivated by human health impacts. Climate change, however, is still awaiting enforceable and mandatory laws to mitigate emissions of greenhouse gases and other climate pollutants.

Miraculously, there is still time to avoid the sort of catastrophic outcomes described in this chapter. What has been overlooked is the fact that integration of the solutions to mitigate climate pollutant emissions will also mitigate air pollution emissions. I will give two major examples:

1. Switching from fossil fuels to renewables, such as solar and wind, and banning biomass burning will not only eliminate carbon dioxide emissions but will also eliminate emissions of sulfates and black carbon, as well as decrease NOx emissions by more than $80 \%$.

2. Likewise, giving renewable energy access to the poorest three billion people can phase out the burning of solid biomass fuels and pave the way for a carbonneutral pathway for the poorest three billion people (or more in the future).

In a companion chapter in this book (Chap. 25), I describe the solutions recommended by a group of 50 researchers from the 10 campuses of the University of California (Ramanathan et al., 2016) and a group of 33 international experts (Ramanathan et al., 2017).

\section{References}

Baccini, A., Walker, W., Carvalho, L., Farina, M., Sulla-Menashe, D., \& Houghton, R. A. (2017) Tropical forests are a net carbon source based on aboveground measurements of gain and loss. Science, 358, 230-234.

Barnosky, A. (2015). Transforming the global energy system is required to avoid the sixth mass extinction. MRS Energy \& Sustainability, 2, E10. https://doi.org/10.1557/mre.2015.11

Cook, B. I., Smerdon, J. E., Seager, R., \& Coats, S. (2014). Global warming and 21 st century drying. Climate Dynamics, 43, 2607-2627. https://doi.org/10.1007/s00382-014-2075-y

Dasgupta, P., \& Ramanathan, V. (2014). Pursuit of the common good, Science, 345, 1457-1458. https://doi.org/10.1126/science.1259406 
Fu, R. (2015). Global warming-accelerated drying in the tropics. Proceedings of the National Academy of Sciences of the United States of America, 112, 3593-3594. https://doi.org/10.1073/ pnas. 1503231112

GBD 2013 Risk Factors Collaborators (2015). Global, regional, and national comparative risk assessment of 79 behavioural, environmental and occupational, and metabolic risks or clusters of risks in 188 countries, 1990-2013: A systematic analysis for the Global Burden of Disease Study 2013. Lancet, 386, 2287-2323.

Holland, G., \& Bruyère, C. (2013). Recent intense hurricane response to global climate change. Climate Dynamics, 42. https://doi.org/10.1007/s00382-013-1713-0

Madden, R. A., \& Ramanathan, V. (1980). Detecting climate change due to increasing $\mathrm{CO}_{2}$ in the atmosphere. Science, 209, 763-768.

Mitchell, D., Heaviside, C., Vardoulakis, S., Huntingford, C., Masato, G., Guillod, B. P., et al. (2016). Attributing human mortality during extreme heat waves to anthropogenic climate change. Environmental Research Letters, 11, 074006.

Mora, C., Dousset, B., Caldwell, I. R., Powell, F. E., Geronimo, R. C., Bielecki, C. R., et al. (2017). Global risk of deadly heat. Nature Climate Change, 7, 501-506. https://doi.org/10.1038/ nclimate 332

Mueller, B., Zhang, X., \& Zwiers, F. W. et al. (2016). Historically hottest summers projected to be the norm for more than half of the world's population within 20 years. Environmental Research Letters, 11, 044011.

Pagani, M., Huber, M., Liu, Z., Bohaty, S.M., Henderiks, J., Sijp, W., et al. (2011). The role of carbon dioxide during the onset of Antarctic glaciation. Science, 334, 1261-1264

Proestos, Y., Christophides, G. K., Ergüler, K., Tanarhte, M., Walkdock, J., \& Lelieveld, J. (2015). Present and future projections of habitat suitability of the Asian tiger mosquito, a vector of viral pathogens, from global climate simulation. Philosophical Transactions of the Royal Society, B: Biological Sciences, 370, 1-16.

Ramanathan, V., Chung, C., Kim, D., Bettge,T., Buja, L., Kiehl, J. T. et al. (2005). Atmospheric brown clouds: Impacts on South Asian climate and hydrological cycle. Proceeding of the National Academy of Science of the United States of America, 102, 5326-5333.

Ramanathan, V., \& Carmichael, G. (2008). Global and regional climate changes due to black carbon. Nature Geoscience, 1, 221-227.

Ramanathan, V., \& Xu, Y. (2010). The Copenhagen Accord for limiting global warming: Criteria, constraints, and available avenues. Proceedings of the National Academy of Sciences of the United States of America, 107, 8055-8062.

Ramanathan, V., Allison, J., Auffhammer, M., Auston, D., Barnosky, A. D., Chiang, L., et al. (2016). Chapter 1. Bending the curve: Ten scalable solutions for carbon neutrality and climate stability. Collabra, 2 (p. 15). Oakland: University of California Press. Retrieved February 9, 2020 from https://doi.org/10.1525/collabra.55

Ramanathan, V., Molina, M. J., Zaelke, D., Borgford-Parnell, N., Xu, Y., Alex, K., et al. (2017). Full: Well under 2 degrees celsius: Fast action policies to protect people and the planet from extreme climate change. Washington, DC: Institute of Governance and Sustainable Development. http://www.igsd.org/wp-content/uploads/2018/03/HLS-Well-Under-2C-VPAS. pdf

Rotstayn, L.D., \& Lohman, U. (2002). Tropical rainfall trends and the aerosol indirect effect. Journal of Climate, 15, 2103-2115. https://doi.org/10.1175/1520-0442(2002)015<3C2103:T RTATI $>3 \mathrm{E} 2.0 . \mathrm{CO} 2$

Russo, S., Sillmann, J., \& Sterl, A. (2017). Humid heat waves at different warming levels. Scientific Reports, 7. https://doi.org/10.1038/s41598-017-07536-7

Samet, J. M., Burke, T., \& Goldstein, B. (2017). The Trump administration and the environmentHeed the science. New England Journal of Medicine, 376, 1182-1188. https://doi.org/10.1056/ NEJMms 1615242 
Thomas, C., Alison, C., Green Rhys, E., Michel, B., Beaumont Linda, J., \& Collingham Yvonne, C. (2004). Extinction risk from climate change. Nature, 427, 145-148. https://doi.org/10.1038/ nature 02121

Urban, M. C. (2015). Climate change. Accelerating extinction risk from climate change. Science (New York, NY), 348, 571-573. https://doi.org/10.1126/science.aaa4984

WMO (2016). Global Climate in 2011-2015. Available at https://public.wmo.int/en/resources/ library/global-climate-2011\%E2\%80\%932015

Xu, Y., Ramanathan, V., \& Washington, W. M. (2016). Observed high-altitude warming and snow cover retreat over Tibet and the Himalayas enhanced by black carbon aerosols. Atmospheric Chemistry and Physics, 16, 1303-1315.

$\mathrm{Xu}$, Y., \& Ramanathan, V. (2017). Well below $2^{\circ} \mathrm{C}$ : Mitigation strategies for avoiding dangerous to catastrophic climate changes. Proceedings of the National Academy of Sciences of the United States of America, 114, 10315-10323.

Open Access This chapter is licensed under the terms of the Creative Commons Attribution 4.0 International License (http://creativecommons.org/licenses/by/4.0/), which permits use, sharing, adaptation, distribution and reproduction in any medium or format, as long as you give appropriate credit to the original author(s) and the source, provide a link to the Creative Commons license and indicate if changes were made.

The images or other third party material in this chapter are included in the chapter's Creative Commons license, unless indicated otherwise in a credit line to the material. If material is not included in the chapter's Creative Commons license and your intended use is not permitted by statutory regulation or exceeds the permitted use, you will need to obtain permission directly from the copyright holder.

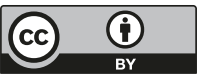

